\title{
A novel approach to visualization of the right ventricular outflow tract
}

\author{
Agata Ewa Kaczyńska (D), Adam Kosiński (D), Rafał Kamiński (iD, \\ Miłosz Andrzej Zajączkowski (D), Marta Gleinert-Rożek (D), \\ Ewa Nowicka
}

Department of Clinical Anatomy, Medical University of Gdańsk, Poland

\begin{abstract}
Introduction: Nowadays, heart is one of the most demanding organs for imaging procedures. This is related to its irregular shape and complex internal structure. Increased demand for imaging complex cardiac structures has resulted in the development of novel 3D modeling techniques. Not only did the methods of imaging the organs of the living patients developed in recent years, but also new methods of post-mortem analysis. Acquired 3D models have a number of applications, both clinical and educational.

Detailed knowledge of the morphology of right ventricular outflow tract (RVOT) is extremely important in terms of cardio-invasive therapeutic procedures. Its significance was noticed during the exploration of the optimal pacing sites in the area of right ventricle. What is more, accurate analysis of the RVOT morphology and spatial structure is also the basis for the treatment of ventricular arrhythmias which foci are located within the outflow tract. The aim of this study was to elaborate the most accurate technique of preparing interior models of the right ventricle and digitizing them to the 3D form. For this purpose we used a silicone molding of the heart cavities with digital photogrammetry.

Keywords: 3D models / cardiac imaging / silicone molding / photogrammetry / right ventricular outflow tract
\end{abstract}

\section{Citation}

Kaczyńska AE, Kosiński A, Kamiński R, Zajączkowski MA, Nowicka E, Gleinert-Rożek M. A novel approach to visualization of the right ventricular outflow tract. Eur J Transl Clin Med. 2018;1(2):36-40.

DOI: $10.31373 /$ ejtcm/100603

\section{Introduction}

The progress of technologies that enable the imaging of complex anatomical structures has resulted in the increased interest in these techniques, in particular in connection with cardiac visualization. Its imaging poses a great challenge, e.g. due to the unique functioning of this organ, the diversity of dimensions and

Corresponding author:

Agata Ewa Kaczyńska, Department of Clinical Anatomy, Medical University of Gdansk, Poland

e-mail: agata.kaczynska@gumed.edu.pl

No external funds.

Available online: www.ejtcm.gumed.edu.pl

Copyright $®$ Medical University of Gdańsk

This is Open Access article distributed under the terms of the Creative Commons Attribution-ShareAlike 4.0 International. 


\section{Material and methods}

shapes depending on the phase of the heart cycle. The visualization of the inside of the heart is extremely demanding due to the complex internal structure of the atria and the chambers [1-3].

Despite obtaining a large amount of the information about the internal structure of the heart, thanks to the use of commonly used imaging techniques, including magnetic resonance, computed tomography and echocardiography [4-6], there is still little attention paid to the structure that is a part of the right ventricle - the outflow tract.

The right ventricular outflow tract (RVOT) is the space located between the supraventricular crest and the pulmonary valve. Exploration of the exact morphological architecture of this structure is extremely important in terms of the cardio-invasive therapeutic procedures. During the search for the optimal stimulation sites from the right ventricle area, it was proved that the most appropriate location for an electrode placement is the RVOT region. It was shown that the stimulation of this area is characterized by a fewer complications compared to the often used stimulation of the apex of the right ventricle [7-8].

Analysis of RVOT morphology is also extremely important in the context of treatment of the ventricular arrhythmias, whose source is located within this area. Accurate assessment of the arrhythmia and the precise location of its foci allows to increase the efficiency of ablation and shorten its duration [9].

Knowledge of the RVOT morphology and its closest neighborhood allows proper optimization of both the implantation of the stimulation system and the ablation of arrhythmogenic foci in this area, as well as limiting the risk of complications. For this purpose, it is extremely important to examine the internal structure of the right ventricle, taking into account the thickness of its muscular wall, the location of vessels and elements of the conductive system, as well as the position of heart valves and cavities in close proximity. Acquiring such information may appear crucial, due to the lack of precise literature data in the subject of the morphological structure of RVOT and its surroundings. Proposing an adequate anatomical nomenclature of this area and determining the exact boundaries of RVOT is a very important aspect of the research, which would significantly improve the work of clinicians.

The aim of this study was to develop an optimal method of obtaining a model of the right ventricle cavity and to transform its physical form into a virtual form that would give the possibility to perform significant measurements of the RVOT area.
30 hearts fixed in a formalin solution were used for the study. Hearts, without macroscopically visible pathological changes, belonged to adults of both sexes.

The first stage of the research was to construct right ventricle models using a silicone molding compound (Xiameter $4250 \mathrm{~S}$ Green). The applied technique has already been used in the case of modeling the heart's appendages [10]. Before modeling, the hearts were thoroughly rinsed with cold water to remove blood clots from the inside. The silicone was poured into the heart cavity from the apex of the right ventricle, because filling RVOT with silicone was more advantageous when it was deposited inside the heart in a gravitational manner, for instance, with the apex pointing upwards. For this purpose, the apex of the right and left ventricles was cut to pour the plastic mass (Figure $1 \mathrm{~A})$. Next, the venous outlets of the right atrium were sutured and a catheter balloon was inserted into the pulmonary trunk above the level of the valve. The catheter balloon was filled with air so as not to distort the surface of the free wall of the RVOT and the pulmonary trunk (Figure 1B, Figure 1C). Thus prepared and dried hearts were placed in a glass vessel with the atria directed towards its bottom and with the apex towards the top (Figure 1D). After preparing the molding mass by adding an activator, the syringe was filled with silicone (Janet $100 \mathrm{ml}$ ), and then the mass was poured into the heart. The tip of the syringe was placed in the incised part of the right ventricle and the silicone was poured inside. Occasionally, the wall of the right ventricle and atrium was slightly pressed to remove air bubbles from among the trabeculations (Figure 1E). When the right part of the heart was completely filled with silicone, the heart was covered tightly with foil. The silicone-filled heart was left to harden for 24 hours. After this time, the ventricular wall was incised along its edge, starting with the incision of the apex of the right ventricle to the base of the right appendage of the heart, including the wall of the right atrium (Figure 1F). After making the incision, the model of the interior of the heart was carefully removed and it was left to dry for 24 hours (Figure 2A, Figure 2B).

The obtained 30 silicone models of the interior of the right heart, including the right atrium and the right ventricle, were subjected to the virtual visualization procedure to form the 3D model. A photogrammetry technique was used which uses serial images of the object in order to transform the physical model into virtual form. A scale was applied to every model, which allows for precise spatial measurements.

With the use of silicone modeling and photogrammetry techniques, 30 RVOT models were obtained. 
Exemplary models and their modifications, as well as exemplary measurements that can be made on the models, are shown in Figure 3A - Figure 3E.

\section{Discussion}

Intensive development of heart imaging techniques, including spatial modeling, allows its more accurate virtual reproduction. Such a model can be subjected to various computer analyses, e.g. specific measurements and simulations. In addition, the 3D model that has been subjected to the appropriate virtual processing can be successfully duplicated to the physical form thanks to the use of the 3D printing technology. Such created 3D heart models, both virtual and those obtained using silicone molding, have

Figure 1 A-F. Stages of RVOT modeling with silicone mass. A - incision of the ventricles apex, B,C - placement of a catheter in the pulmonary trunk, D - placement of the heart in the glass vessel, $\mathrm{E}$ - pouring the molding mass, $\mathrm{F}-$ incision of the ventricle and atrium in order to take out done model

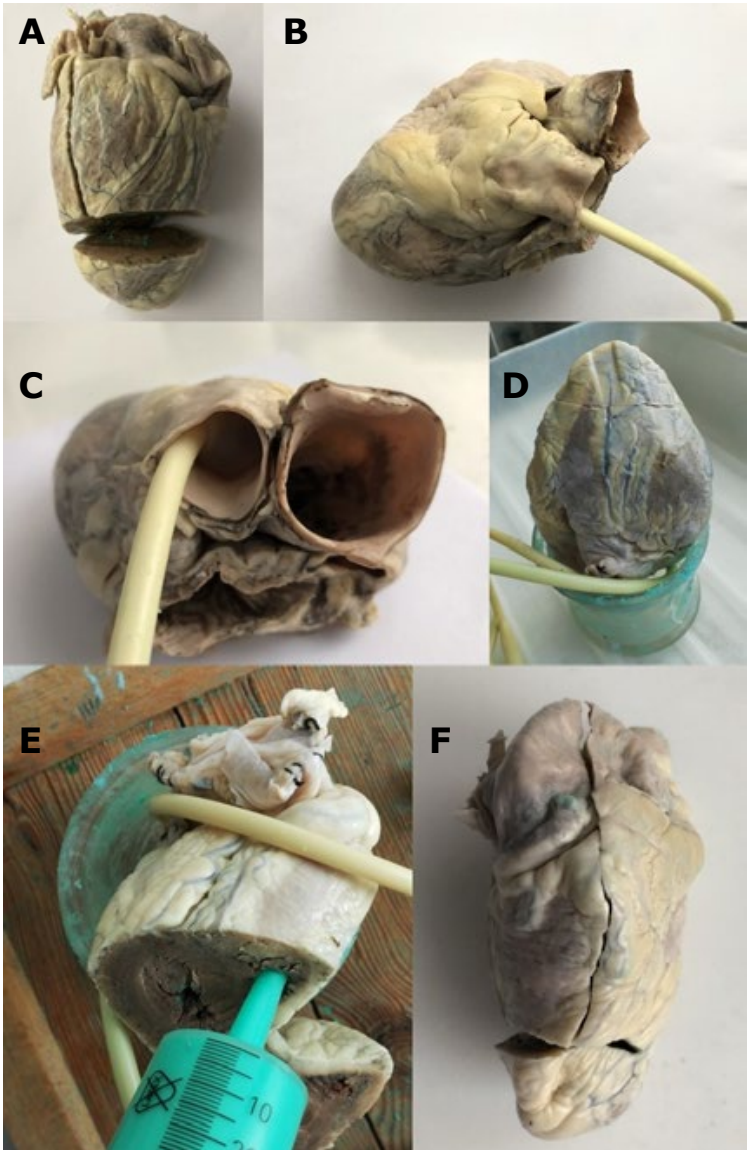

a number of applications in many areas of medicine. Computer simulations give the opportunity to explore the exact anatomy of the heart and help to understand the structural defects of this organ. What is more, the virtual heart model makes it possible to analyze some physiological aspects without carrying out complicated in vivo tests [11-13].

According to some reports 3D models of the hearts of patients with complex cardiac disease were constructed in order to plan the optimal surgical approach [14]. Commonly used methods of cardiac imaging were used for this purpose: computed tomography and magnetic resonance. Next, a 3D model was printed which was based on the virtual heart model that accurately reflected the patient's heart and defect. Such a model helped during the search for the most advantageous method of the resection of the aneurysm of the ventricle and the tumor in the right ventricle, as well as the reconstruction of the area after excision of the lesion. What is more, the surgeon was also able to estimate the risk of complications of the planned surgery and to choose the technique with the least risk of failure.

Figure 2 A, B. Finished model of the interior of right atrium and right ventricle

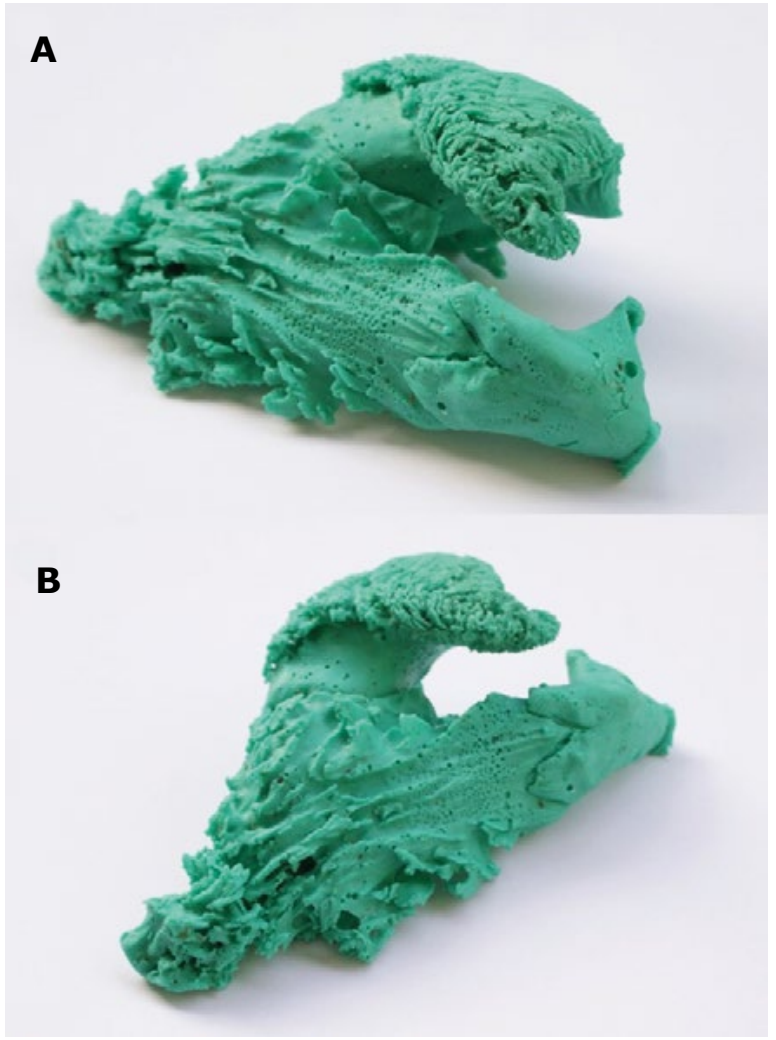


A

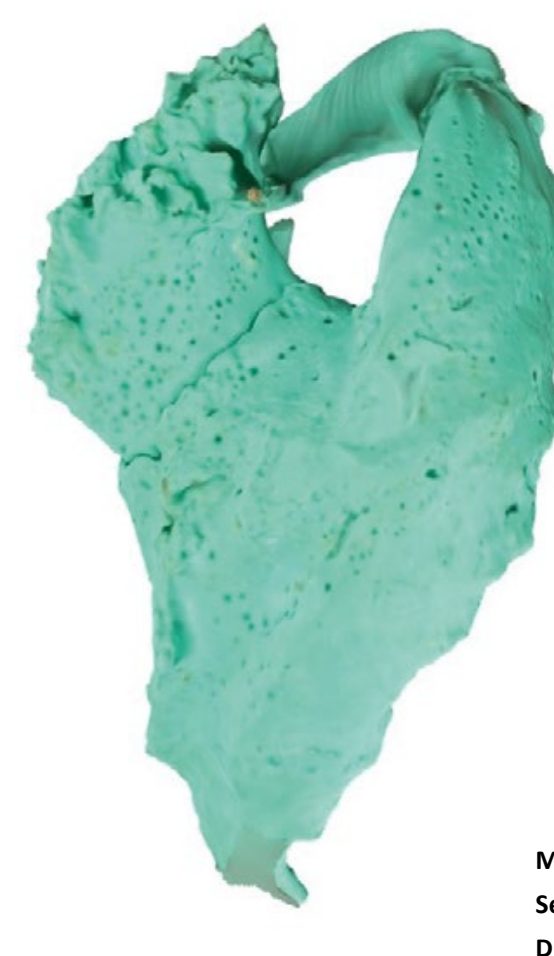

B

D
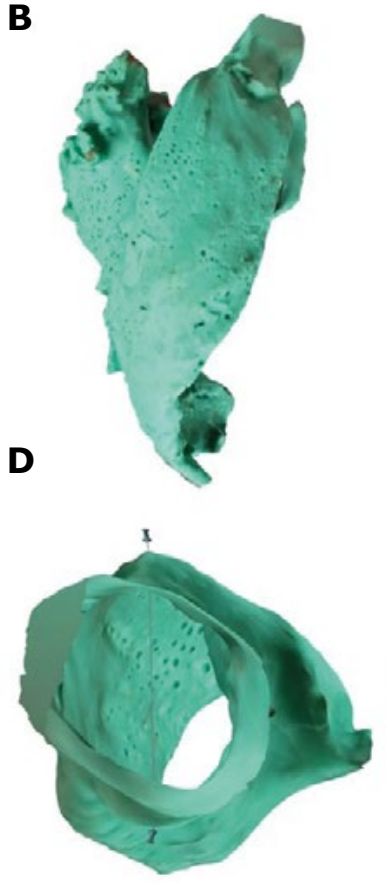

Measure

Select two points

Distance: $2.468 \mathrm{~cm}$

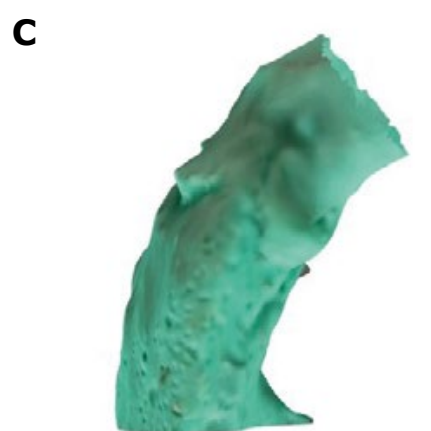

E

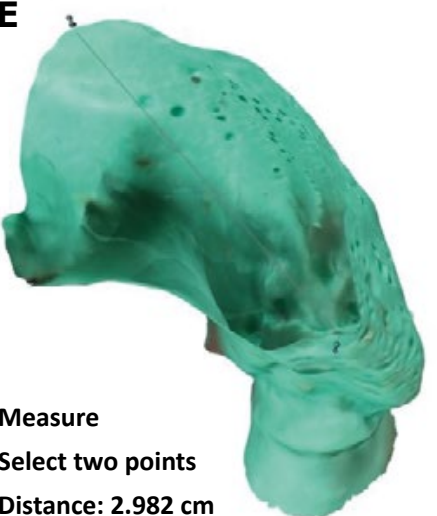

A - 3D model of the right ventricle and right atrium, B - view of the right ventricle and RVOT, C - separated view of RVOT and pulmonary valve, D - section through RVOT and exemplary measurement, E - exemplary measurement of RVOT

Modeling the heart with the use of 3D technology is also widely used in the case of valve defects. In Vukicevic et al., a mitral valve replacement was performed - specific for a given patient's case - using images obtained by transesophageal 3D echocardiography and computed tomography [15]. In Maragiannis et al., also on the basis of the images from computed tomography, a copy of the patient's severely stenotic aortic valve was constructed [16]. It was also proven that such models are not only a source of information about the structure of the valve defect, but also retain the functional properties of a given defect. Such models are an ideal material for planning valve reconstruction and for designing the most beneficial tools for in this type of surgery. This was also proven in the work of Schievano et al., where on the basis of the images obtained from magnetic resonance imaging, the RVOT model and the pulmonary trunk were made to analyze the possibility of percutaneous implantation of the pulmonary valve [17].

The wide range of applications of in vivo heart modeling with the use of imaging methods is an extremely important element of cardiac diagnostics. However, possibility of mapping post-mortem structures should be also mentioned, both in the case of normal hearts and those with defects. Grabherr et al. compared the post-mortem imaging techniques, taking into account their advantages and disadvantages [18]. The photogrammetry method was mentioned as one that does not require a large financial investment, in particular if other methods of post-mortem imaging of structures are not available, for example, scanners that use a beam of light. The authors also emphasized that in addition to its low cost, the most important advantages of the photogrammetry are the simplicity of this method and the availability of various computer so$\mathrm{ftware}$ that support this technique. In addition, a model made with the use of the photogrammetry retains its natural color, which is extremely important in forensic medicine.

The procedure of the photogrammetry and the characteristics of its accuracy were described by Bobkowska et al. [19]. That study showed that the silicone model of the right ventricular interior, which was virtualized using photogrammetry and then scaled, is suitable for analyzing the shape and size of the structure. The use of imaging and visualization techniques has also become more important in these areas of medical sciences which deal with biometric analysis in the context of face modeling and its correct identification 
[20]. An accurate reflection of the dimensions and spatial structure of a given object is undoubtedly a great advantage of modern virtualization methods, thanks to which they are widely used, particularly in medical sciences.

\section{Conclusions}

Post-mortem heart modeling with the use of the molding mass and then transforming a given model into a virtual form combines methods that are primarily characterized by low cost and ease of performing a 3D heart model. The obtained virtual models are widely used because they can be used for measurement analysis and to modify a given spatial model. In addition, the acquired heart model can be reproduced using 3D printing.
The models of the interior of the heart provide an ideal source of information on the morphological structure and spatial architecture of the interior of the ventricles and atria. The combination of both techniques, molding the heart with silicone and photogrammetry are the original approach to obtaining information about the internal structure of the right ventricle, in particular the RVOT, which still attracted too little attention. Due to existing inconsistencies in the morphology of this area, boundaries and spatial structure, RVOT is a very interesting cardiac component for anatomical research. The results of such studies may be useful for many clinicians in their daily work. The use of 3D RVOT modeling will contribute to the acquisition of additional information about the morphology of this area and may be the basis for further research related to, for example, determining the location of other structures in the close vicinity of the RVOT.

\section{References}

1. Kim MS, Hansgen AR, Wink O, Quaife RA, Carroll JD. Rapid prototyping: A new tool in understanding and treating structural heart disease. Circulation. 2008;117(18):2388-94.

2. Greil GF, Wolf I, Kuettner A, Fenchel M, Miller S, Martirosian P, et al. Stereolithographic reproduction of complex cardiac morphology based on high spatial resolution imaging. Clin Res Cardiol. 2007;96(3):176-85.

3. Lopez-Perez A, Sebastian R, Ferrero JM. Three-dimensional cardiac computational modelling: methods, features and applications. Biomed Eng Online. 2015;14(1):1-31.

4. Machaj I, Janczewska E, Truszewski Z, Trzebicki J, Gaciong Z. Nieinwazyjne badania obrazujące w kardiologii. Med Ogólna i Nauk o Zdrowiu. 2015;21(4):362-8.

5. Greil GF, Beerbaum P, Razavi R, Miller O. Imaging the right ventricle. Heart. 2008;94(6):803-8.

6. Sonecki P. Nowe techniki w kardiologii: echokardiografia 3D. Kardiol po Dyplomie. 2010;9(11):36-45.

7. Ho SY, Nihoyannopoulos P. Anatomy, echocardiography, and normal right ventricular dimensions. Heart. 2006;92(SUPPL. 1):2-14.

8. Lieberman R, Grenz D, Mond HG, Gammage MD. Selective site pacing: defining and reaching the selected site. Pacing Clin Electrophysiol. 2004;27(6 Pt 2):883-6.

9. Pytkowski M, Maciąg A, Sterliński M, Jankowska A. Lokalizacja ogniska arytmii u chorych z zaburzeniami rytmu serca pochodzącymi z drogi odpływu prawej komory. Folia Cardiol Excerpta. 2006;1(4):211-20.

10. Kamiński R, Kosiński A, Brala M, Piwko G, Lewicka E, Dąbrowska-Kugacka A, et al. Variability of the left atrial appendage in human hearts. PLoS One. 2015;10(11):1-9.

11. Trunk P, Mocnik J, Trobec R, Gersak B. 3D heart model for computer simulations in cardiac surgery. Comput Biol Med. 2007;37(10):1398-403.

12. Dankowski R, Baszko A, Sutherland M, Firek L, Kałmucki P, Wróblewska K, et al. 3D heart model printing for preparation of percutaneous structural interventions: description of the technology and case report. Kardiol Pol. 2014;72(6):546-51.

13. Rao AS, Menon PG. Presurgical planning using image-based in silico anatomical and functional characterization of Tetralogy of Fallot with associated anomalies. Interact Cardiovasc Thorac Surg. 2015;20(2):149-56.

14. Jacobs S, Grunert R, Mohr FW, Falk V. 3D-Imaging of cardiac structures using 3D heart models for planning in heart surgery: a preliminary study. Interact Cardiovasc Thorac Surg. 2008;7(1):6-9.

15. Vukicevic M, Mosadegh B, Min JK, Little SH. Cardiac 3D Printing and its Future Directions. J Am Coll Cardiol Img. 2017;10(2):171-84.

16. Maragiannis D, Jackson MS, Igo SR, Schutt RC, Connell P, Grande-Allen J, et al. Replicating Patient-Specific Severe Aortic Valve Stenosis with Functional 3D Modeling. Circ Cardiovasc Imaging. 2015;8(10):e003626.

17. Schievano S, Migliavacca F, Coats L, Khambadkone S, Carminati M, Wilson N, et al. Percutaneous pulmonary valve implantation based on rapid prototyping of right ventricular outflow tract and pulmonary trunk from MR data. Radiology. 2007;242(2):490-7.

18. Grabherr S, Egger C, Vilarino R, Campana L, Jotterand M, Dedouit F. Modern post-mortem imaging: an update on recent developments. Forensic Sci Res. 2017;2(2):52-64.

19. Bobkowska K, Przyborski M, Kaczyńska A, Kosiński A. Digital Photogrammetry in the Analysis of the Ventricles' Shape and Size. In: Proceedings - 2017 Baltic Geodetic Congress (Geomatics), BGC Geomatics 2017. 2017. p. $169-73$. 